\title{
Treatment comparison of femoral shaft with femoral neck fracture: a meta-analysis
}

Yao Lu ${ }^{\dagger}$, Yakang Wang ${ }^{\dagger}$, Zhe Song ${ }^{\dagger}$, Qian Wang, Liang Sun, Cheng Ren, Hanzhong Xue, Zhong Li, Kun Zhany Dingjun Hao, Yang Zhao ${ }^{*}$ and Teng Ma*

\section{Abstract}

Background: To compare the efficacy and complications between reconstruction nailand. "ow screw+plate in patients with femoral shaft and femoral neck fracture.

Methods: The full text of studies on clinical efficacy involving reconstruction nail and h, ow screw+plate was retrieved from multiple databases. Review Manager 5.0 was adopted for meta- lalysis, sensitivity analysis, and bias analysis. The meta-analysis was conducted with respect to the operatio tip rod loss, healing time of the femoral shaft, healing time of the femoral neck, and complications. Finally, studies met the eligibility criteria, including 991 patients.

Results: The meta-analysis suggested better characteristics for the recon:tuction nail compared with the hollow screw+plate regarding operation time $(\mathrm{OR}=-82.41,95 \% C L[-91.72, \quad 73.10], P<0.00001$; $P$ for heterogeneity $<$ $0.00001, P=98 \%)$, blood loss $(\mathrm{OR}=-388.01,95 \% \mathrm{Cl}[-42<.95,-33.06], P<0.00001 ; P$ for heterogeneity $<0.00001, P$ $=99 \%)$, healing time of femoral shaft $(\mathrm{MD}=-3.89,95 \% \mathrm{C} \quad 4.74-3.05], P<0.00001$; $P$ for heterogeneity $<0.00001$, $P=99 \%)$, healing time of femoral neck $(\mathrm{MD}=-4.04,95 \% \mathrm{Cl}, 1.33,-3.75], P<0.00001 ; P$ for heterogeneity $=0.008$, $P=60 \%)$, and complications (OR=0.47,95\% Cl [6. $P$. $P=0.0006$; $P$ for heterogeneity $=1.00, P=0 \%$ ).

Conclusion: This meta-analysis shows that a $r$ construs $n$ hail is a more efficient and safer treatment than a hollow screw+plate for patients with femoral shaft ano moral neck fracture.

Keywords: Reconstruction nail, Holloy/ screw, Plate $/$ emoral shaft with femoral neck fracture

\section{Background}

A femoral shaft combined wi moral neck fracture is a common condition. The in 1 dence of this injury accounts for about $10 \%$ the tatal incidence of femoral shaft fractures. oral shaft and femoral neck fracture re mos caused by trauma [1-3]. When the $\mathrm{b} p$ in the flexion abduction position, and the / see is the flexion position, the assault from th front and the inertia of the body result in an axial ce. It the femoral shaft fracture cannot abson 11 the nergy, the residual force is transmitted th camoral neck, resulting in femoral neck fractu [4-6]. If the hip is in the adduction position when $\mathrm{it}$ is injured, the posterior dislocation of the hip often occurs in addition to the fracture of the femoral head.

Although the treatment of the femoral neck with femoral shaft fracture is difficult, several methods have been reported $[7,8]$. In this study, the femoral reconstruction nail fixation, the plate system fixation, and the hollow nail fixation are discussed. Femoral reconstruction nail fixation has the following advantages: (a) fixation of the two fractures, axis fixation, and control of the length in multiple femoral shaft fractures and (b) closure of the pin, avoid damaging to local blood circulation, avoid peeling off the local periosteum, and minimal trauma. Meanwhile, the reconstruction nails have the following shortcomings:

\footnotetext{
*Correspondence: zy881027@126.com; gukemt@163.com

†Yao Lu, Yakang Wang and Zhe Song contributed equally to this work. Department of Orthopaedic Surgery, HongHui Hospital, Xi'an Jiaotong University, Xi'an 710054, Shaan'xi Province, China
}

(c) The Author(s). 2020 Open Access This article is distributed under the terms of the Creative Commons Attribution 4.0 International License (http://creativecommons.org/licenses/by/4.0/), which permits unrestricted use, distribution, and reproduction in any medium, provided you give appropriate credit to the original author(s) and the source, provide a link to the Creative Commons license, and indicate if changes were made. The Creative Commons Public Domain Dedication waiver (http://creativecommons.org/publicdomain/zero/1.0/) applies to the data made available in this article, unless otherwise stated. 
(a) great technical difficulty and the surgery should take into account both reduction and fixation, especially in the displacement of femoral neck fracture reduction and fixation operation and (b) femoral neck fractures can be shifted and rotated while placing a pin [9-11].

The advantages of the plate system in fixing the femoral shaft fracture and hollow nail in fixing the femoral neck fracture include simple operation, direct reduction, and control of the femoral shaft rotation. However, the disadvantages of large trauma, excessive bleeding, extensive peeling of periosteum, and high probability of nonunion were reported [12, 13]. The main complications of femoral shaft combined with femoral neck fracture include nonunion of the femoral neck fracture, femoral head necrosis, coxa varus deformity, nonunion of the femoral shaft fracture, and malunion [14].

Several articles have compared these two methods, encompassing various research designs, recruitment and exclusion criteria, and measurements. Currently, only a few meta-analyses have compared the reconstruction nail and hollow screw+plate. Therefore, a meta-analysis was conducted to evaluate the clinical efficacy and safety of these two methods comprehensively.

\section{Methods \\ Search strategy}

The comparison between reconstruction nail and hollow screw+plate was comprehensively analyzed. The references from January 2010 to October 2018 were ched from PubMed, Springer, Embase, Wiley Blackwen d Chinese Journal Full-text Database.

Two authors searched the articres spendently using the following keywords: (1) reconstry,ction nail; (2) hollow screw; (3) femoral : ft; and (4) femoral neck. These search terms m as o ued using "and" to search the databas for related articles. In order to obtain add to lo revent studies with high accuracy, the reference of each retrieved article was also revieyed.

\section{Citation selection}

All article $c_{+}$or the first screening were further examined by two thy researchers. The titles and abstracts of these articles, were screened independently and stringe. If the study was relevant, the full-text article was obtai d.

The following inclusion criteria were required to be fulilled by the included studies:

(1) A randomized control trial study or a controlled clinical trial study;

(2) Comparison of the treatment between reconstruction nail and hollow screw+plate;

(3) Availability of full-text.

Exclusion criteria:

(1) Not a randomized study;

(2) Studies on other treatments other than reconstruction nail or hollow screw+plate;

(3) Studies are lacking outcome measures or comparable results.

Finally, two different researchers jointly identified the articles. Subsequently, whether the study fulfilled the above requirements or not was examined. In case of any discrepancy or disagreement, a third investigator was consulted for consensus.

\section{Search results}

10 studies finally included A preliminary search in the electronic database retrieved 362 related titles and abstracts. After a thorough review, 10 articles were found to fulfill all the inclusion criteria. The remaining 352 articles were excluded due to the following reasons: repeated,
Fig. 1 Schematic of the study identification and inclusion and exclusion criteria 
Table 1 Characteristic of the included studies

\begin{tabular}{|c|c|c|c|c|c|c|c|}
\hline Study & Year & Language & Country & Age range (mean) & Groups & $n$ & Years of onset \\
\hline \multirow[t]{2}{*}{ Akgul [15] } & 2016 & English & Turkey & $17.6 \pm 1.8$ & Reconstruction nail & 5 & September 2007 to June 2013 \\
\hline & & & & & Hollow screw+plate & 10 & \\
\hline \multirow[t]{2}{*}{ Boese [16] } & 2016 & English & Germany & $18.2 \pm 2.1$ & Reconstruction nail & 8 & October 2008 to June 2010 \\
\hline & & & & & Hollow screw+plate & 9 & \\
\hline \multirow[t]{2}{*}{ Genest [17] } & 2018 & English & Germany & $54.7 \pm 12.1$ & Reconstruction nail & 15 & الر \\
\hline & & & & & Hollow screw+plate & 15 & \\
\hline \multirow[t]{2}{*}{ Jiang [18] } & 2015 & English & China & $62.4 \pm 18.7$ & Reconstruction nail & 233 & \\
\hline & & & & & Hollow screw+plate & 233 & \\
\hline \multirow[t]{2}{*}{ Kovala k[19] } & 2017 & English & Turkey & $74.1 \pm 4.1$ & Reconstruction nail & 13 & ary 2015 \\
\hline & & & & & Hollow screw+plate & & \\
\hline Maranho [20] & 2018 & English & America & $22.3 \pm 1.7$ & Reconstruction nail & & \\
\hline Oh [21] & 2017 & English & Japan & $78.2 \pm 7$ & Reconstru & & August 2015 to February 2017 \\
\hline Ripamonti [22] & 2014 & English & Italy & $68.4 \pm 9.5$ & Reconst & 38 & April 2000 to March 2010 \\
\hline \multirow[t]{2}{*}{ Sangeux [23] } & 2015 & English & Australia & $56.7 \pm 2.3$ & Recor & 11 & February 2002 to June 2010 \\
\hline & & & & & & 11 & \\
\hline \multirow[t]{2}{*}{ Yamauchi [24] } & 2016 & English & Japan & $72.1 \pm 1$ & & 101 & January 2010 to January 2012 \\
\hline & & & & & & 99 & \\
\hline
\end{tabular}

irrelevant studies, no control groups, incr. lete dat or comparisons, other operations, reviews, on ncomplete articles. Figure 1 presents a schematic or the identification, inclusion, and exclu on criteria of the studies, thereby summarizing the $s$ ch rocess and the reasons for exclusion.

\section{Data extraction}

Two reviewers read fu toxt and extracted the relevant data from fach s ty into Microsoft Excel. The characteristics extracted from each study included the first author's name, publication year, year of onset, sample size (reconstruction nail/hollow screw+plate), the age range of patients, and outcome parameters with respect to the treatment of reconstruction nail and hollow screw+plate.

\section{Statistical analysis}

Meta-analysis was performed by Revman 5.0 (Cochrane Collaboration, 2011) to assess the differences in the

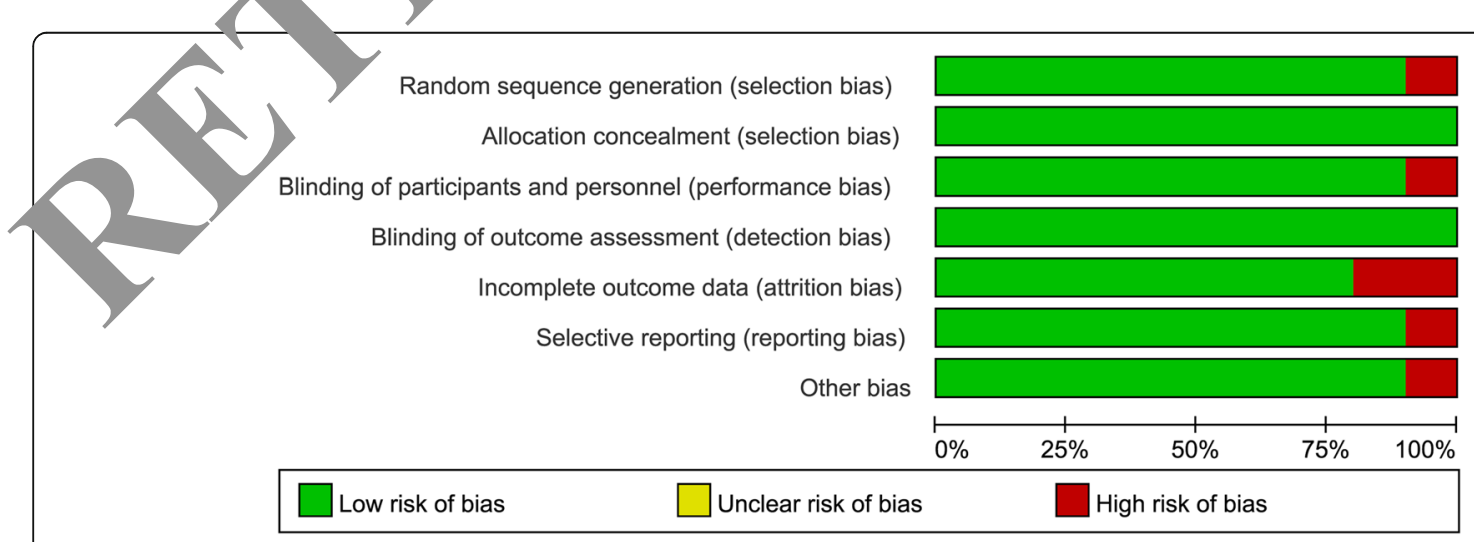

Fig. 2 Assessment of the quality of the included studies: low risk of bias (green hexagons), unclear risk of bias (yellow hexagons), and high risk of bias (red hexagons) 


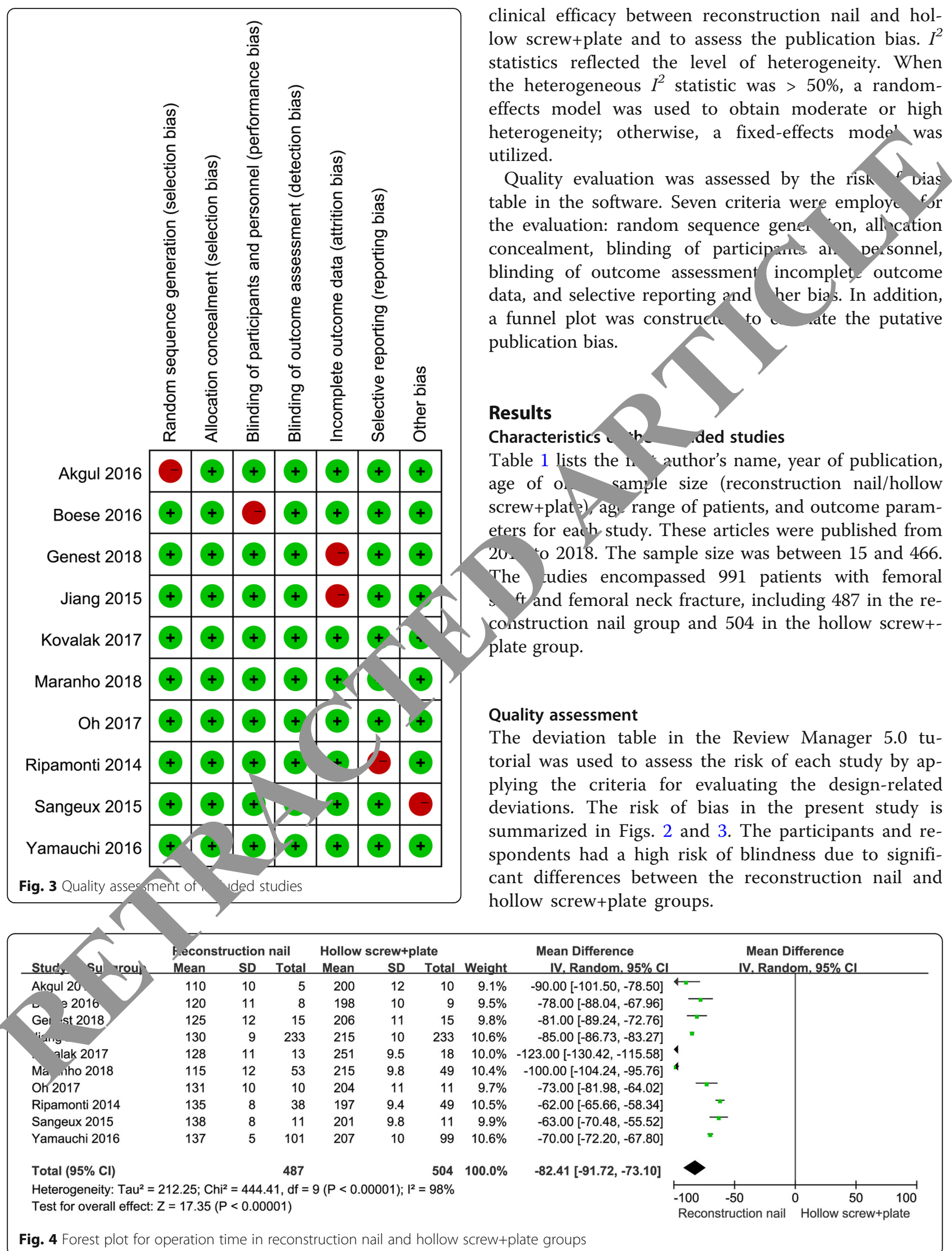




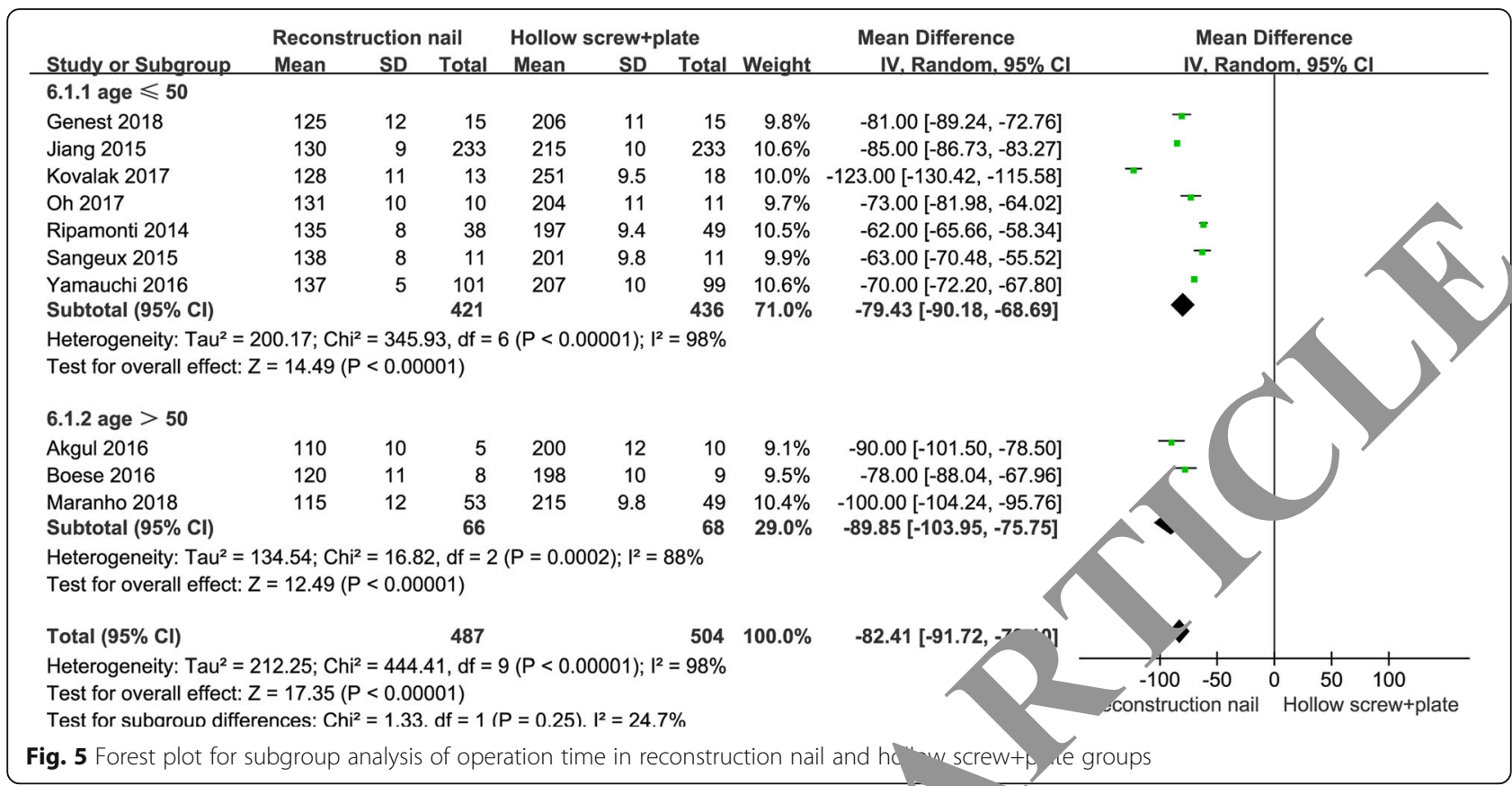

\section{Results of meta-analysis}

\section{Meta-analysis on the operation time}

A total of 10 studies were focused on the duration of the operation. Figure 4 illustrates the operation time of the reconstruction nail and hollow screw+plate o up Moreover, statistically significant differences were served in the operation time between recons tion na. and hollow screw+plate. The current metarana. is suggested a significant difference in the operation tir se between the reconstruction nail and ollow screw+plate (odds ratio $(\mathrm{OR})=-82.41,95 \%$ conf nce i terval $(\mathrm{CI})$ : - 91.72 to $-73.10, P<0.000 \quad P$ for neterogeneity $<$ $\left.0.00001, I^{2}=98 \%\right)$. The operatio $\quad$ ie of the hollow screw+plate was higher $n$ that of the reconstruction nail. When the dat wer sategorized into two subgroups according calage he 1 value changed from 98 to $24.7 \%$ (Fig. 5)

\section{Meta-analysis on the blood loss}

11. forest plot for meta-analysis on blood loss is lepic $d$ in Fig. 6. The results demonstrated that the od loss in the hollow screw+plate group was higher than that with reconstruction nail (OR $=-388.01,95 \%$ CI: -422.95 to $-353.06, P<0.00001$; $P$ for heterogeneity $\left.<0.00001, I^{2}=99 \%\right)$. In the subgroup analysis of blood loss, the $I^{2}$ value changed from 99 to $0 \%$ (Fig. 7).

\section{Meta-analysis on the healing time of femoral shaft}

The included studies on the healing time of the femoral shaft are shown in Fig. 8. The overall result indicated that the healing time of femoral shaft with hollow screw+plate was higher than that with reconstruction nail $(\mathrm{MD}=-3.89,95 \% \mathrm{CI}:-4.74$ to $-3.05, P<$ 0.00001; $P$ for heterogeneity $<0.00001, I^{2}=99 \%$. In the

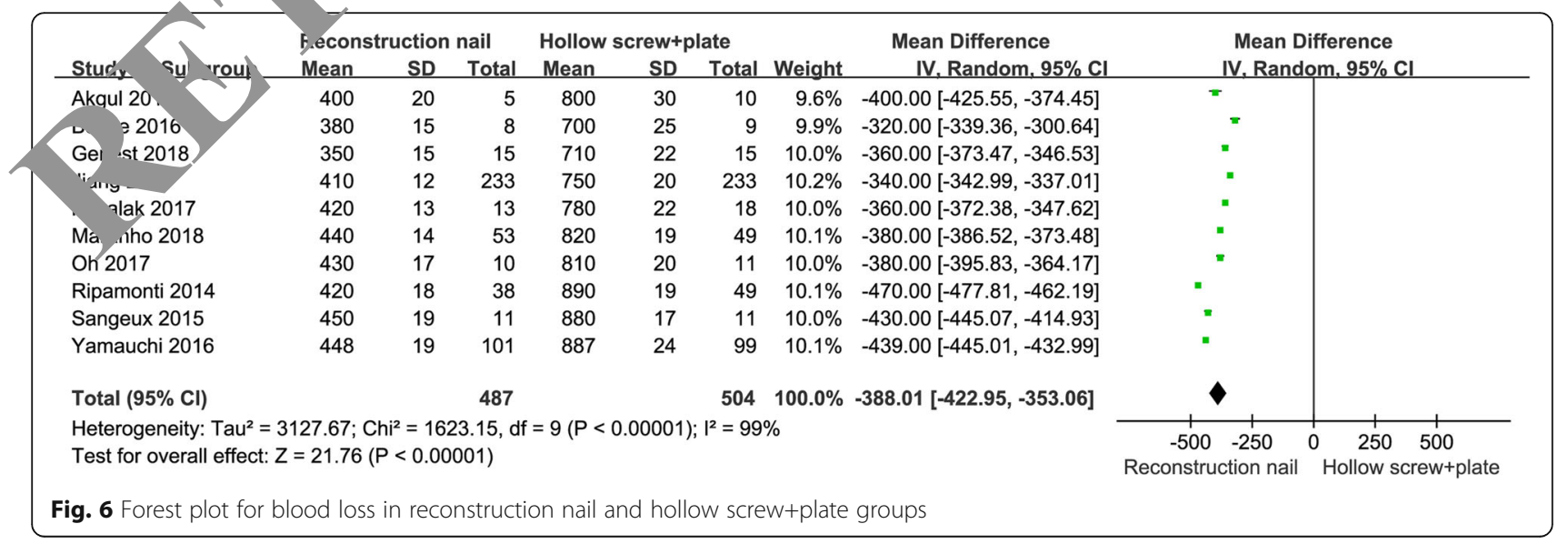




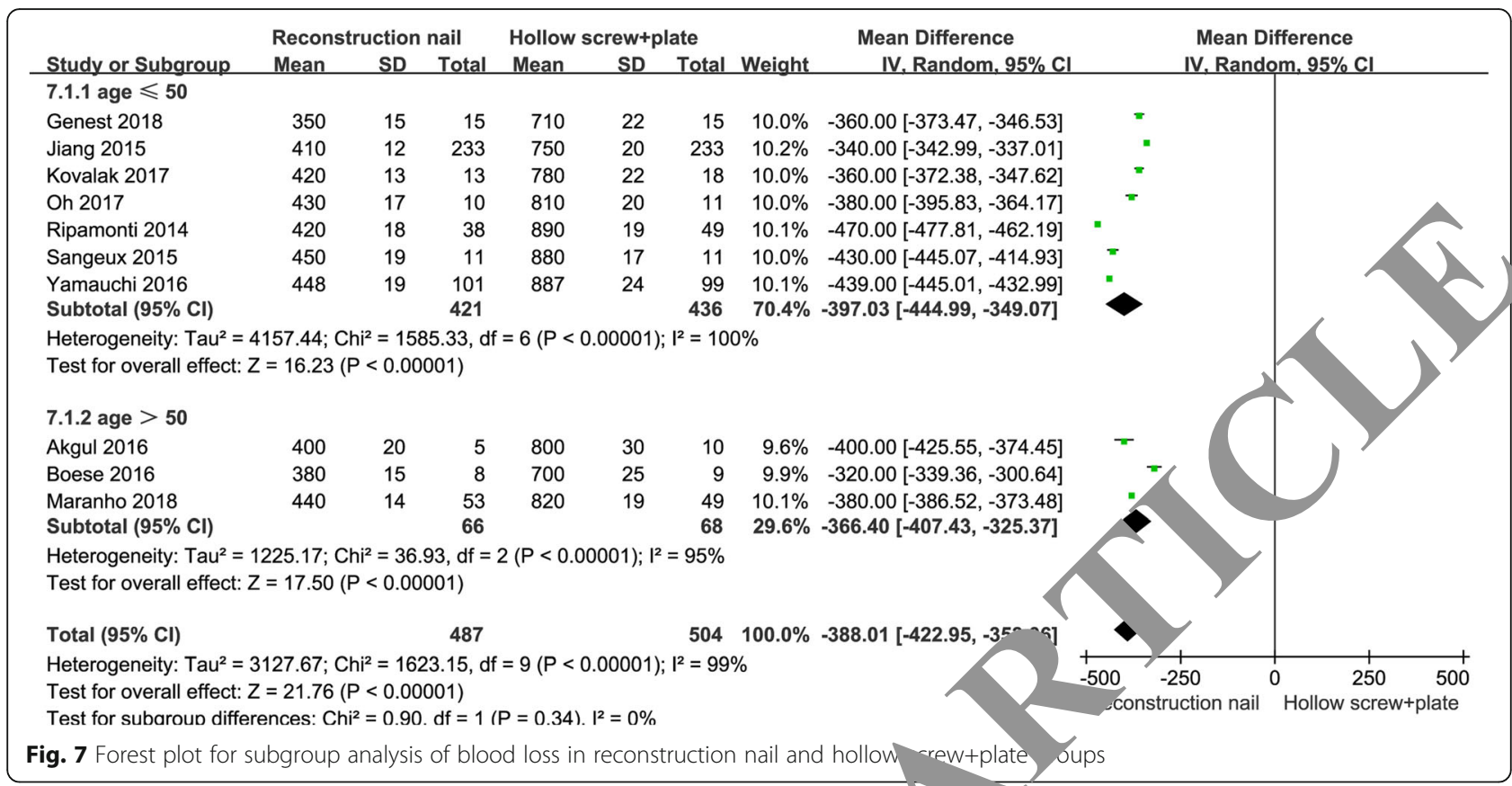

subgroup analysis for the healing time of the femoral shaft, the $I^{2}$ value changed from 99 to $66.7 \%$ (Fig. 9).

\section{IVIc Tnalysis about complications}

The cticles addressing the complications of surgery included. As shown in Fig. 11, significant difference in the complication between reconstruction nail and hollow screw+plate was observed, and the incidence with hollow screw+plate was higher than that with reconstruction nail $(\mathrm{OR}=0.47,95 \% \mathrm{CI}$ : $0.31-0.73, P=0.0006$; $P$ for heterogeneity $\left.=1.00, I^{2}=0 \%\right)$. femoral neck (Fig. 10). Statistically significant), ifferences were detected between the construction nail and hollow screw+plate, and the mbi ed results showed that patients require more healing time for the femoral neck in hollow screy. ate as compared to the reconstruction $(\mathrm{ML}=-4.04,95 \% \mathrm{CI}$ : 4.33 to $-3.75, P<0.0$ for heterogeneity $=$ $\left.0.008, I^{2}=60 \%\right)$

\section{Sensitivity analysis}

According to the meta-analysis, the heterogeneity of the operation time was high $\left(I^{2}=98 \%\right)$. As shown in Fig. 12, the low heterogeneity of the operation time might be attributed to the different results of each study. After

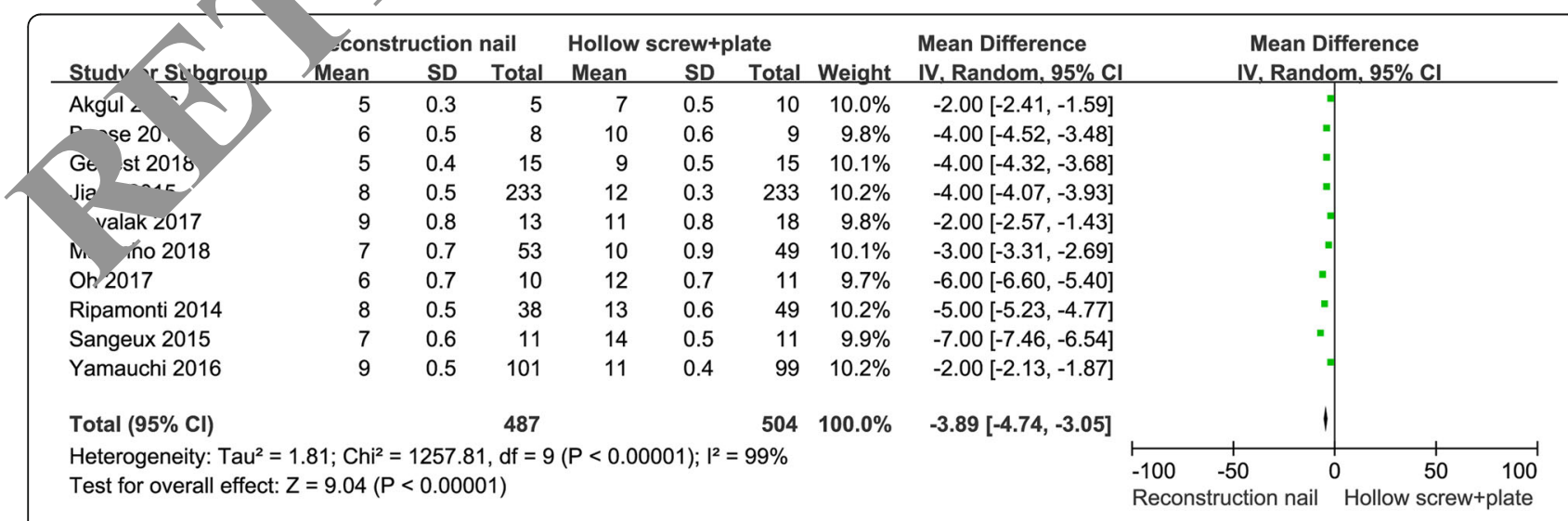

Fig. 8 Forest plot for healing time of femoral shaft in reconstruction nail and hollow screw+plate groups 


\begin{tabular}{|c|c|c|c|c|c|c|c|c|c|}
\hline \multirow{3}{*}{$\begin{array}{l}\text { Study or Subgroup } \\
8.1 .1 \text { age } \geqslant 50\end{array}$} & & \multicolumn{4}{|c|}{ Hollow screw+plate } & \multirow{3}{*}{$\begin{array}{l}\text { Mean Difference } \\
\text { IV. Random, } 95 \% \mathrm{Cl}\end{array}$} & \multirow{2}{*}{$\begin{array}{c}\text { Mean Difference } \\
\text { IV. Random, } 95 \% \mathrm{CI}\end{array}$} \\
\hline & Mean & SD & Reconstruction nall & \multirow[t]{2}{*}{ Mean } & \multirow[t]{2}{*}{ SD } & \multirow[t]{2}{*}{ Total } & Weight & & \\
\hline & & & & & & & & & IV. Random, $95 \% \mathrm{Cl}$ \\
\hline Genest 2018 & 5 & 0.4 & 15 & 9 & 0.5 & 15 & $10.1 \%$ & $-4.00[-4.32,-3.68]$ & $=$ \\
\hline Jiang 2015 & 8 & 0.5 & 233 & 12 & 0.3 & 233 & $10.2 \%$ & $-4.00[-4.07,-3.93]$ & - \\
\hline Kovalak 2017 & 9 & 0.8 & 13 & 11 & 0.8 & 18 & $9.8 \%$ & $-2.00[-2.57,-1.43]$ & $=$ \\
\hline Oh 2017 & 6 & 0.7 & 10 & 12 & 0.7 & 11 & $9.7 \%$ & $-6.00[-6.60,-5.40]$ & \\
\hline Ripamonti 2014 & 8 & 0.5 & 38 & 13 & 0.6 & 49 & $10.2 \%$ & $-5.00[-5.23,-4.77]$ & $=$ \\
\hline Sangeux 2015 & 7 & 0.6 & 11 & 14 & 0.5 & 11 & $9.9 \%$ & $-7.00[-7.46,-6.54]$ & \\
\hline Yamauchi 2016 & 9 & 0.5 & 101 & 11 & 0.4 & 99 & $10.2 \%$ & $-2.00[-2.13,-1.87]$ & 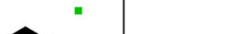 \\
\hline Subtotal $(95 \% \mathrm{Cl})$ & & & 421 & & & 436 & $70.1 \%$ & $-4.28[-5.34,-3.22]$ & \\
\hline \multicolumn{10}{|c|}{$\begin{array}{l}\text { Heterogeneity: } \text { Tau }^{2}=2.02 ; \mathrm{Chi}^{2}=1178.10, \mathrm{df}=6(P<0.00001) ; I^{2}=99 \% \\
\text { Test for overall effect: } Z=7.89(P<0.00001)\end{array}$} \\
\hline \multicolumn{10}{|l|}{ 8.1.2 age $<50$} \\
\hline Akgul 2016 & 5 & 0.3 & 5 & 7 & 0.5 & 10 & $10.0 \%$ & $-2.00[-2.41,-1.59]$ & \\
\hline Boese 2016 & 6 & 0.5 & 8 & 10 & 0.6 & 9 & $9.8 \%$ & $-4.00[-4.52,-3.48]$ & \\
\hline Maranho 2018 & 7 & 0.7 & 53 & 10 & 0.9 & 49 & $10.1 \%$ & $-3.00[-3.31,-2.69]$ & \\
\hline Subtotal $(95 \% \mathrm{Cl})$ & & & 66 & & & 68 & $29.9 \%$ & $-2.99[-3.99,-1.99]$ & \\
\hline \multicolumn{10}{|c|}{$\begin{array}{l}\text { Heterogeneity: } \mathrm{Tau}^{2}=0.73 ; \mathrm{Chi}^{2}=36.17, \mathrm{df}=2(P<0.00001) ; \mathrm{I}^{2}=94 \% \\
\text { Test for overall effect: } Z=5.86(P<0.00001)\end{array}$} \\
\hline Total $(95 \% \mathrm{Cl})$ & & & 487 & & & 504 & $100.0 \%$ & & \\
\hline \multicolumn{10}{|c|}{$\begin{array}{l}\text { Heterogeneity: } \mathrm{Tau}^{2}=1.81 ; \mathrm{Chi}^{2}=1257.81, \mathrm{df}=9(P<0.00001) ; \mathrm{I}^{2}=99 \% \\
\text { Test for overall effect: } Z=9.04(P<0.00001) \\
\text { Test for subaroun differences: } \mathrm{Ch}^{2}=3.01 . \mathrm{df}=1(\mathrm{P}=0.08) . \mathrm{I}^{2}=66.7 \%\end{array}$} \\
\hline
\end{tabular}

excluding the study by Kovalak (2017), $I^{2}$ was altered to $97 \%$, which supported the robustness of this study.

\section{Bias analysis}

Funnel plots of operation time with recons tion na. and hollow screw+plate were constructed, inc ing all the studies. The results showed mode ate symmet $y$ and little publication bias (Fig. 13). The sult of Fgger's test did not provide any significant ev ce of potential publication bias $(t=1.22, P=(\sim 7)$.

\section{Discussion}

A femoral shaft frac e c mhined with a femoral neck fracture is a relativly s ous injury. In recent years, the litera re reports an upward trend of the fracture [15]. increase in the incidence of this combined fracture is attributed to the increased awareness of the fracture and the improvement of first aid ability to improve the patients' life quality $[15,16]$. A majority of the fracture is caused by trauma. Typically, indirect violence occurring along the femoral shaft causes hip flexion, abduction, and knee flexion.

In the case of femoral shaft fracture combined with femoral neck fracture, surgery is better than traction. Nonetheless, the reconstruction of the intramedullary nail is an optimal choice $[17,18]$. The design of the femoral reconstruction intramedullary nail conforms to the physiological axis of the human femur and belongs to

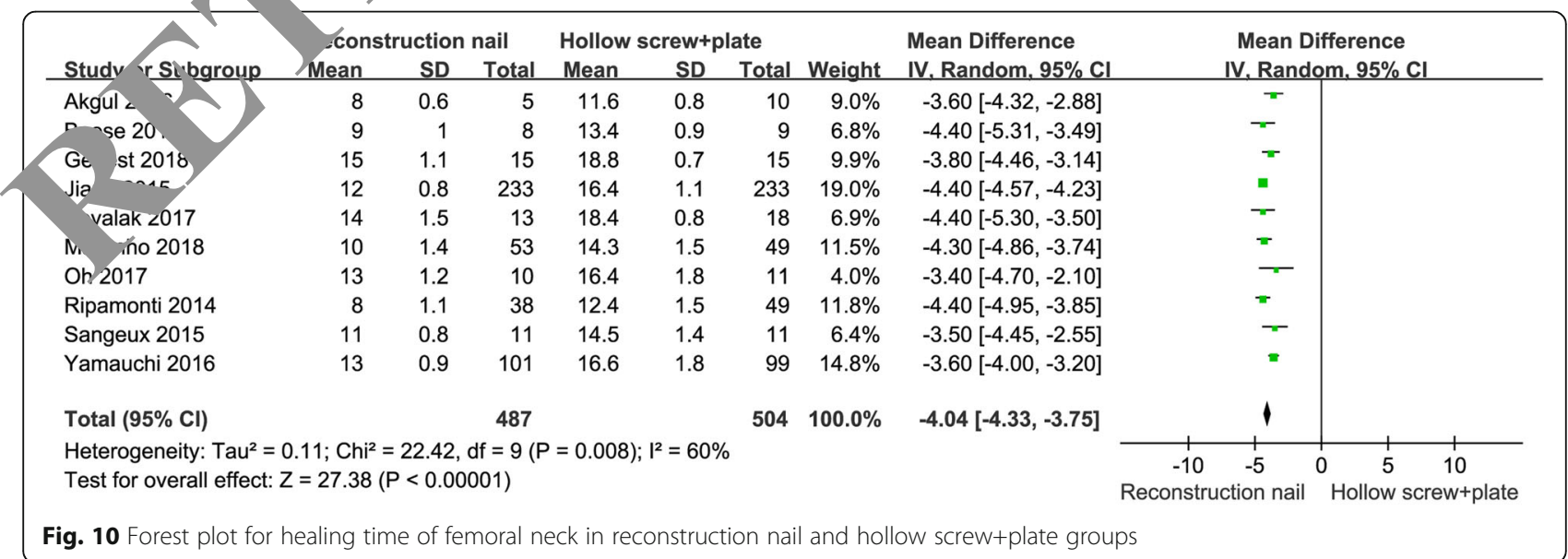




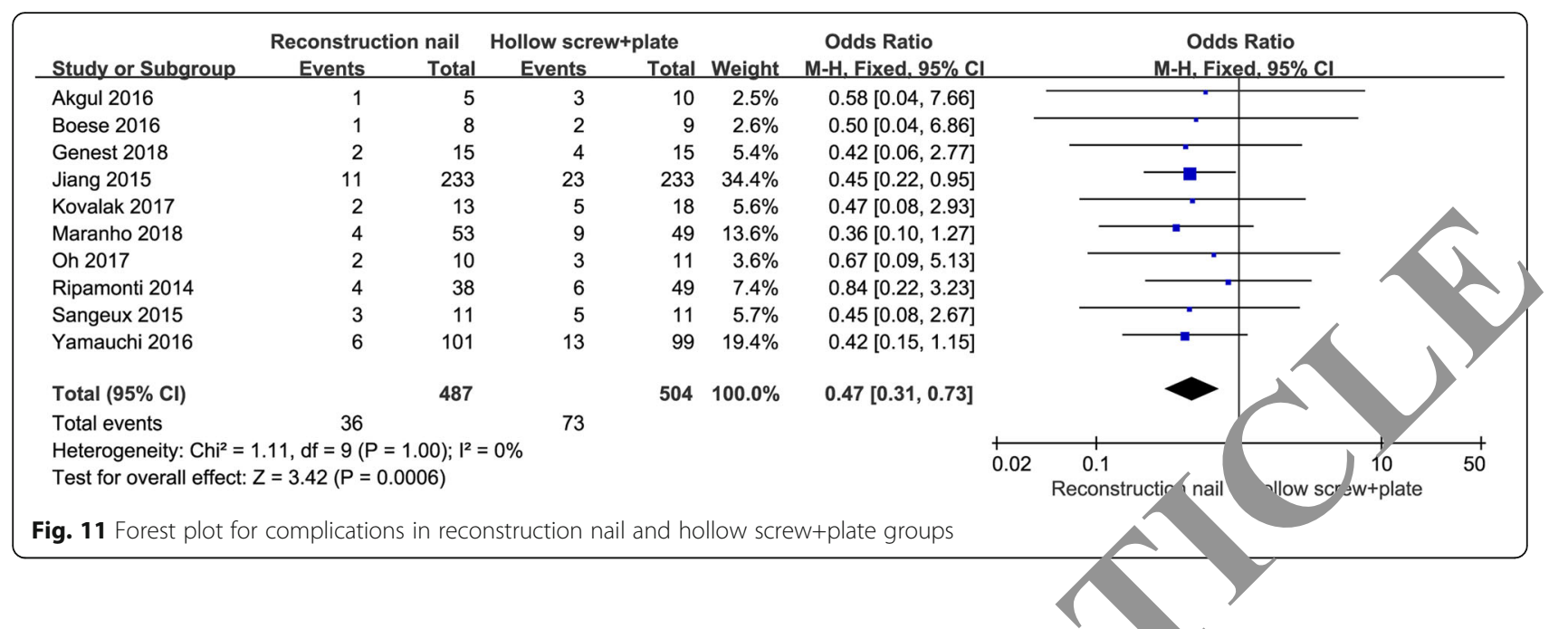

the central internal splint frame structure. Additionally, fretting at the fracture end during early movement or partial weight-bearing can promote callus growth.

The plate system femoral shaft fracture fixation with cannulated nail femoral neck fracture fixation presents the advantages of simple operation, direct reduction, and effectively reduces the incidence of femoral shaft rotation [19]. However, defects such as large surgical trauma, important bleeding, and high probability of non-w/10n of plate fixation exist.

Currently, only limited studies have comparcuthe construction nail and hollow screw+plate femor. shaft with femoral neck fracture. Morecver, th indicators and sample sizes were restricted furthermory, additional indicators and an increase sample size are needed for deeper study. In this stua the $d$ fference in the operation time and the he ' $n$ o time of the femoral shaft and femoral neck in the res, cruction nail and hollow screw+plate gr was significant. Thus, this phenomenon demon ate that a reconstruction nail is a better treatment a nollow screw+plate with respect to cliniral e cacy. This result was similar to that by Song at el., $b$ ported the reconstruction nail was deemed a in e efficient therapy than a hollow screw+plà -18l.

The conpris $n$ of blood loss and complications revealed that the value in the hollow screw+plate group Wa ignificantly higher than that in the reconstruction nail $\varepsilon$ oup. Watson and Moed stated that a reconstrucGail is a safer treatment than a hollow screw+plate, which is consistent with the current results [19].

All the results demonstrated that a reconstruction nail is better therapy than a hollow screw+plate in the treatment of patients with femoral shaft and femoral neck fracture. These results were coincident with those previous researches. In the present study, low heterogeneities of meta-analyses were obtained, and according to the funnel plots, no publication bias was observed, which also supported the current results.

Taken together, those results suggest that the reconstruction nail is probably a better treatment option than the hollow screw+plate for the management of patients

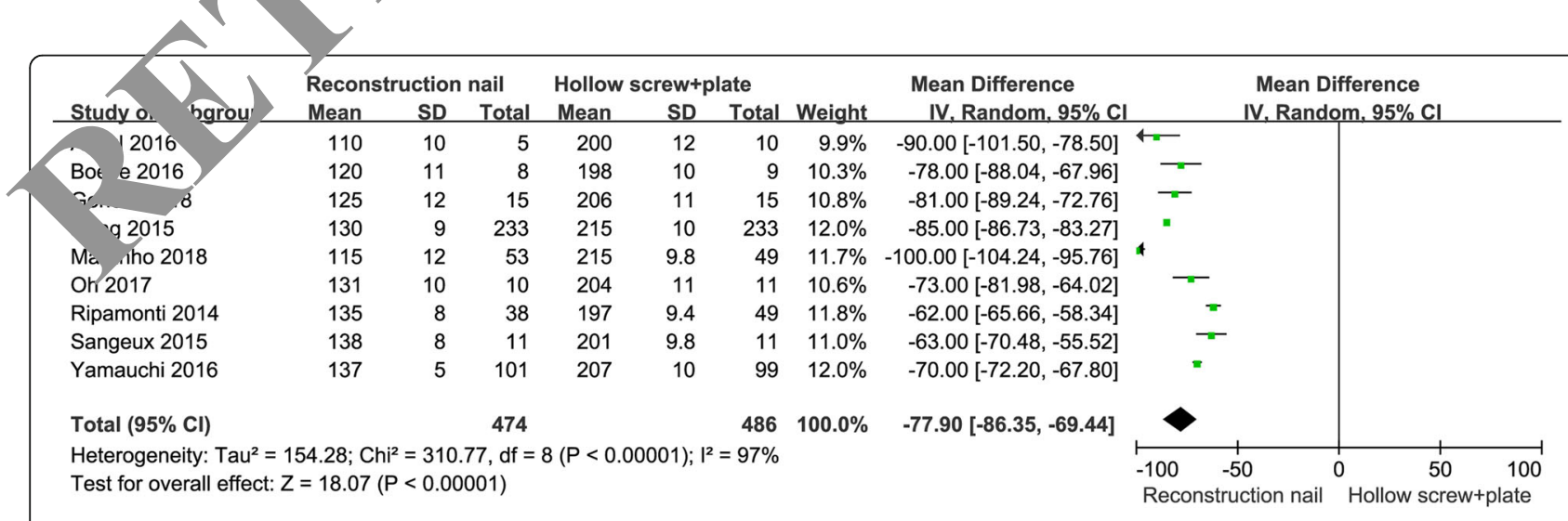

Fig. 12 Forest plot for the sensitivity analysis in operation time between reconstruction nail and hollow screw+plate groups 

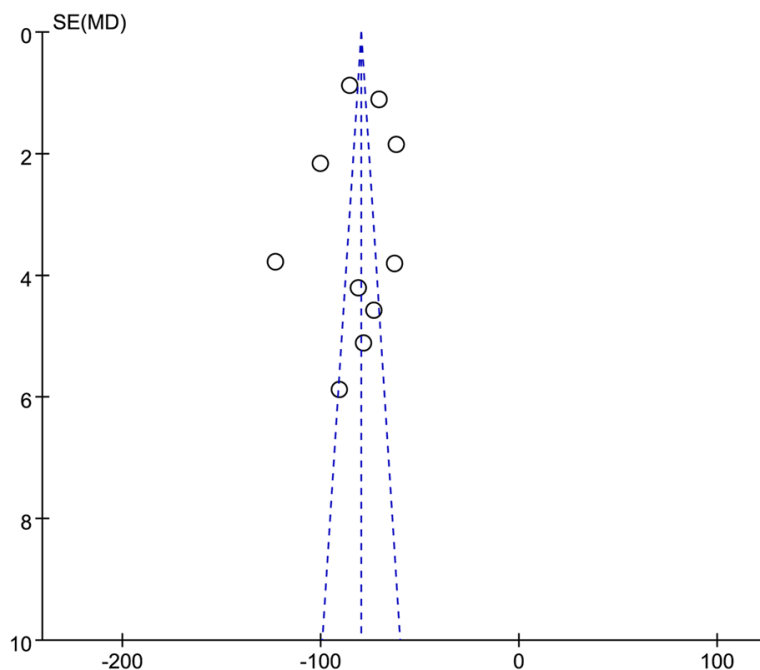

Fig. 13 Begg's funnel plot of publication bias

with femoral shaft and neck fractures. The reconstruction nail has definitive advantages in healing time, union rates, and complications. We consider that the reconstruction nail should be the first choice in most patients.

Nevertheless, the present study had some limitations. First, the indicators and comparisons in this study were limited, which indicated that more indexes need to De analyzed and evaluated in future studies. Second is. cluded countries were limited, and data in more co tries are essential and should be assesse in futur studies. Third, the experience of the surgeons is not consistently reported, precluding any nalysis of $\mathrm{th} s \mathrm{~s}$ factor. Fourth, heterogeneity among st dies regarding the patients, surgical settings, and devic used may limit the conclusions.

\section{Conclusion}

In conclusion, the ren mota-analysis demonstrated the comparison betwee econstruction nail and hollow screw+plate. I th clini $A$ efficacy and safety, the reconstruction hail rendered as an optimal therapy than a hollow screw+plate.

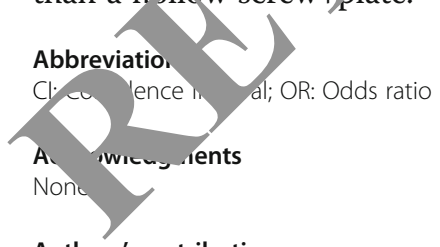

Authors' contributions

$\mathrm{TM}, \mathrm{YZ}$, and $\mathrm{YL}$ conceived and designed the study. $\mathrm{YL}, \mathrm{QW}$, and $\mathrm{LS}$ participated in the acquisition of data. YKW and ZS analyzed and interpreted the data. $Y L$ and $Y K W$ drafted the article. $C R, H Z X$, and $Z L$ critically revised the article. KZ and DJH contributed to important intellectual content. All authors gave final approval of the version to be submitted.

\section{Funding}

This work was supported by the Project of Science and Technology Department of Shaanxi Province (2013 k14-02-12, 2015SF110, 2015SF116,
2016SF-304). The funder 1 go role in study design, data collection and analysis, dec to publisi, or preparation of the manuscript

Availability of ata and materials

The datasets use $\mathrm{d}$ and/or analyzed during the current study are available

iro corresponding author on reasonable request.

hics sproval and consent to participate

an plicable.

Zonsent for publication

Not applicable.

Competing interests

The authors declare that they have no competing interests.

Received: 11 September 2019 Accepted: 27 November 2019

Published online: 20 January 2020

\section{References}

1. Barei DP, Schildhauer TA, Nork SE. Noncontiguous fractures of the femoral neck, femoral shaft, and distal femur. J Trauma. 2003;55(1):80-6.

2. Brown CU, Yeni YN, Norman TL. Fracture toughness is dependent on bone location--a study of the femoral neck, femoral shaft, and the tibial shaft. J Biomed Mater Res. 2000:49(3):380-9.

3. Chai JW. Treatment of femoral shaft and neck fractures with reconstructional interlocking intramedullary nail. Chongqing Medicine. 2008.

4. Desai YJ, Gupta R, Patel RA, Musa RA, Sharma SB, Upadhyay AS, et al. Study of results of ipsilateral fracture neck and shaft femur operated by proximal femoral interlocking nail. 2008.

5. Gao Z, Shen H, Fan J, Orthopedics DO, Hospital SD, Shunyi B. The clinical study in treatment with nails of ipsilateral femoral shaft and neck fractures. Capital Medicine. 2014.

6. Graves M. Femoral neck fracture fixation in the setting of ipsilateral femoral neck and shaft fractures. Techniq Orthopaed. 2010;25(3):148-54.

7. Heiney JP, Leeson MC, Vrabec GA. Delayed diagnosis of an ipsilateral femoral neck fracture with an associated femoral shaft fracture in light of a negative computed tomography scan. J Trauma. 2009;67(4):E129-31.

8. Hossam ElShafie M, Adel Morsey H, Emad EY. Ipsilateral fracture of the femoral neck and shaft, treatment by reconstruction interlocking nail. Arch Orthop Trauma Surg. 2001;121(1-2):71-4.

9. Huang XK, Yang ZY. Clinical analysis of ipsilateral fracture of shaft of femur and affiliated femoral neck. J Modern Clin Med. 2010.

10. Jain P, Maini L, Mishra P, Upadhyay A, Agarwal A. Cephalomedullary interlocked nail for ipsilateral hip and femoral shaft fractures. Injury. 2004;35(10):1031-8. 
11. Konig G, van Bergen P, Suren EG. Femoral shaft fracture and secondary diagnosis of ipsilateral femoral neck fracture. Typical constellation or a complication of the distal femoral nail (DFN)? Unfallchirurg. 2002;105(7):656-9.

12. Liu TG. Surgical treatment method and clinical effect of 68 cases with femoral shaft fracture complicated with ipsilateral femoral neck fracture. Chin Pract Med. 2015.

13. McDonald LS, Tepolt F, Leonardelli D, Hammerberg EM, Stahel PF. A cascade of preventable complications following a missed femoral neck fracture after antegrade femoral nailing. Patient Saf Surg. 2013;7(1):16.

14. O'Toole RV, Dancy L, Dietz AR, Pollak AN, Johnson AJ, Osgood G, et al. Diagnosis of femoral neck fracture associated with femoral shaft fracture: blinded comparison of computed tomography and plain radiography. J Orthop Trauma. 2013;27(6):325-30.

15. Oh CW, Oh JK, Park BC, Jeon IH, Kyung HS, Kim SY, et al. Retrograde nailing with subsequent screw fixation for ipsilateral femoral shaft and neck fractures. Arch Orthop Trauma Surg. 2006;126(7):448-53.

16. Pajarinen J, Lindahl J, Savolainen V, Michelsson O, Hirvensalo E. Femoral shaft medialisation and neck-shaft angle in unstable pertrochanteric femoral fractures. Int Orthop. 2004;28(6):347-53.

17. Shang Q, Zhang F, O. D. Orthopaedics, Treatment of ipsilateral femoral neck and shaft fracture with PFNA. J Luzhou Medical College. 2014

18. Song KS, Ramnani K, Cho CH, Bae KC, Lee K, Son ES. Ipsilateral femoral neck and shaft fracture in children: a report of two cases and a literature review. J Orthop Traumatol. 2013;14(2):147-54.

19. Watson JT, Moed BR. Ipsilateral femoral neck and shaft fractures: complications and their treatment. Clin Orthop Relat Res. 2002;399:78-86.

20. Maranho DA, Davila-Parrilla A, Miller PE, Kim Y-J, Novais EN, Millis MB. Acetabular morphology in slipped capital femoral epiphysis: comparison at treatment onset and skeletal maturity. J Child Orthop. 2018;12: https://doi. org/10.1302/1863-2548.12.180057.

21. Y. Oh, et al., Location of atypical femoral fracture can be determined by tensile stress distribution influenced by femoral bowing and neck-shaft angle: a CT-based nonlinear finite element analysis model for the assessment of femoral shaft loading stress, Injury. 2017. https://doi.c $4 / 10$ 1016/j.injury.2017.09.023.

22. Ripamonti C, Lisi L, Avella M. Femoral neck shaft angle width s associa with hip-fracture risk in males but not independently of fe neck bor density. Br J Radiol. 2014;87:20130358. https://doi.org/1C 259, 0130358 .

23. Sangeux M, Pascoe J, Graham HK, Ramanauskas F, C2 T. ThreeDimensional Measurement of Femoral Neck Ante Jersion and Neck, naft Angle. J Comput Assist Tomogr. 2015;39: 83-85 ttps://doi.org/10.1097/RCT. 0000000000000161.

24. Yamauchi K, Naofumi M, Sumida H, Fukuta S, Hol sam arison of morphological features in the femur be n femoral neck fractures and femoral intertrochanteric fractures. 2016. hitp grg/10.1007/s00276-0161626-9.

\section{Publisher's Note}

Springer Nature remair s neutral regard to jurisdictional claims in published maps ans tutional at, ations.

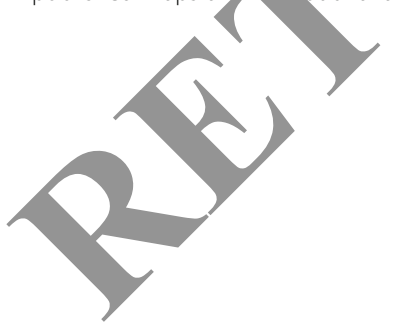

Ready to submit your research? Choose BMC and benefit from:

- fast, convenient online submission

- thorough peer review by experienced researchers in your field

- rapid publication on acceptance

- support for research data, including large and complex data types

- gold Open Access which fosters wider collaboration and increased citations

- maximum visibility for your research: over $100 \mathrm{M}$ website views per year

At $\mathrm{BMC}$, research is always in progress.

Learn more biomedcentral.com/submissions 